\title{
Efficient technology of human resources management in the field of transport
}

\author{
Victoria Lez'er ${ }^{1}$, Irina Muratova ${ }^{1}$, Alexander Grigorev ${ }^{2}$, Anna Kopytova ${ }^{1, *}$ \\ ${ }^{1}$ Tyumen Industrial University, Volodarskogo str., 38, Tyumen, 625000, Russia \\ ${ }^{2}$ Tyumen State University, Volodarskogo str., 6, Tyumen, 625001, Russia
}

\begin{abstract}
The authors of the article strive to give an analysis of the main aspects of human resource management technology in the practice of transport companies, to identify the problematic issues of their development and to find solutions. The article discusses the criteria for effective human resource management, analyzes the conditions for monitoring the quality of human resource use in a transport company, describes the characteristics of grading as an effective management technology for the motivational component of the personnel in the transport sector. As an experimental base of research, the authors used monitoring the quality of human resources in transport companies of the city of Tyumen - Evrobus 72, IntelInvest, ComfortAuto Tyumen, as well as textual and graphical materials of reports.
\end{abstract}

\section{Introduction}

The dynamics in the development of transport in recent years emphasizes the urgent need for adequate and purposeful management of human resources. They are the driving force that is capable of overcoming critical moments in the development of a transport enterprise, a subsector, or the entire transport industry. According to the data of empirical research, the policy of human resource management directly affects the natural and monetary indicators of production: economic benefits, income level, value of shares.

In the current economic situation, the development of effective human resource management is crucial for most transport organizations. The main tasks for administrative structures and stakeholders of transport organizations are development of innovation policy to optimize professional activity through improving personnel management, improving the level of corporate culture and creating a positive image of companies.

The relevance of this work is determined by the need to improve the productivity and competitiveness of the transport sector, more efficiently use the professional competence of its specialists, increase personnel stability and motivational component by using innovative personal management technologies; as well as by the need for research and analysis of the experience of using modern human resource management policies in domestic and foreign

\footnotetext{
${ }^{*}$ Corresponding author: a.copytowa@yandex.ru
} 
transport companies to implement an effective strategy for managing organizational synergies and increasing the importance of human capital in the field of transport.

The concept of "human resource management", often denoted by the acronym HRM contains a system of interactive connections between personnel and administrative structures, as well as the socio-psychological aspect of managing an organization. The objectives of human resource management are to ensure a decent level of organization of work of employees, in order to maximize their economic and socio-psychological satisfaction of their professional activities and the maximum possible benefit of their level of competence for the employer.

The purpose of this study is to analyze the main aspects of human resource management technology in the practice of transport companies, to identify the problematic issues of their development and to identify solutions.

Management of human resources in the field of transport considers such issues as:

- the synergistic potential of the labor force of a transport company in the context of an overall development strategy (the number of necessary organizational structures, the company's image, a program to improve corporate culture, etc.);

- synergistic costs required for the preparation of a qualified workforce in the context of strategic policy to develop the quality of goods or passenger traffic, reduce financial costs, profit margins, and so on.;

The policy of human resource management is formed primarily by theoretical and practical achievements of the psychology of professional activity and personnel management, including issues of compliance with the level of competence of the position held, professional suitability, research of motivation and satisfaction of employees' needs, development of necessary rules and procedures to establish psychologically comfortable interactions between the company and its staff.

The article discusses the criteria for effective human resource management, analyzes the conditions for monitoring the quality of human resource use in a transport company, describes the characteristics of grading as an effective management technology for the motivational component of the personnel in the transport sector. As an experimental base of research, there was used monitoring the quality of human resources utilization in the transport companies of the city of Tyumen - Evrobus 72, IntelInvest, ComfortAuto Tyumen, as well as textual and graphical materials of reports.

\section{Methods}

1. Criteria for effective human resource management.

In order to develop a research methodology, it is necessary to clarify the criteria for effective human resource management. According to a study by representatives of the Harvard Business School (Beer et al., 1985 - the concept of 4C - competence, commitment, congruency, cost-effectiveness), it is correct to monitor the effectiveness of human resource management policies based on the following aspects:

1) Competence, that reflects the level of professional qualifications of staff, their ability to self-presentation, self-control, the continuous development of their knowledge, skills, abilities and the potential for a transition to a more qualified degree. This direction is correctly assessed using the staff certification system according to the officially approved list of general cultural and professional competencies.

2) Commitment, that is, the commitment of employees to their professional community and company, as a team united by a single mission, a high level of work motivation and corporate spirit. Monitoring of the level of commitment should be conducted based on the opinions and views of employees, statistics of fines, dismissals, absenteeism, expert analysis of personal conversations with staff. 
3) Congruency, which means the unity of administrative structures and staff in an effort to achieve greater success of their company, common views and efforts in the implementation of common goals. In an effectively managed company, staff at all levels combine corporate aspirations for common prosperity and future prospects. The main criterion for team coordination is a favorable socio-psychological climate in the team, the absence of conflicts and the latent activity of "informers".

4) Cost-effectiveness is determined by the level of costs in the context of the overall efficiency of the entire process of the transport company. It is important to use human resources with the maximum productivity of their advantages, rather than command-andcontrol methods. The policy of any transport company should be based on the desire to get the maximum amount of profit by spending the least amount of economic and social resources. This is achieved by the ability of top-level managers to promptly respond to dynamic processes in the labor market and the socio-economic environment.

2) Monitoring the quality of human resources utilization in a transport company

The solution to the problem of the efficiency of the transport company is based primarily on the qualitative use of human potential. It is necessary to analyze the available labor resources in quantitative and qualitative assessments, identify the need for their growth or reduction, and develop mechanisms for their formation.

The effectiveness and timeliness of the implementation of all transport operations, the efficiency of the processes associated with the use of machinery or other equipment depend on the organization of the company's labor resources and their effective use. As a result, the company has increased traffic volumes, while reducing their cost and progression in terms of profitability in general. Rational use of staff is a prerequisite for the smoothness of the transport process and the successful implementation of the established plan.

Personnel work of the transport company is engaged in identifying a shortage of specialists or in excess of their number, creating a base of vacant posts, redeveloping staff, developing staffing tables, etc..

3) Monitoring the level of competence and professional reliability of an employee.

The efficiency of the transport sector is due to the level of professionalism, qualifications, health, motivation, degree of efficiency and psychological stability of staff.

Currently, there is relevant theoretical and practical direction of work on combining the key criteria of financial analysis with transport psychology and economic studies of cognitive, social and psychological factors of human behavior.

The 5-step approach is effective in implementing a policy of increasing productivity, passenger and freight traffic, expanding opportunities and means for the sustainable development of transport companies. There is the structure of the main aspects of human resource management, in the context of the economic analysis of the transport sector:

1. Financial and economic sustainability of the transport sector

2. efficiency of transport business processes

3. human resource management

4. SBD (set of balanced data) and KPI of the personnel

5. The system of measures to improve staff KPI

The complexity and diversity of the tasks facing the workers in the transport sector determine the difficulty in choosing criteria for the qualitative monitoring of their level of competence, performance and technology. This monitoring should include continuous observation and registration of biomedical, psycho-physiological and emotional parameters of workers, as well as qualification, educational and functional assessments.

4. Grading, as an effective management technology of the motivational component of the transport sector personnel

One of the current management technologies of the motivational component of the staff is the grading technology, that represents comprehensive monitoring of employees, 
including certain indicators and criteria. This technology is based on a unique methodology that has already positively recommended itself in a number of companies and even entire industries, although there are quite a few critical opinions about the correctness of its implementation. The main advantages of grading that made it popular include openness, fairness, lack of subjectivization, and reliability of the assessment process. In the opinion of many managers, the quality of grading data allows them to manage staff more rationally, increase the synergistic aspect of the company's work, and reduce the latency of costs.

The content of grading technology has a general idea regardless of the type of activity of the organization or the type of industry: the grade level is determined by the degree of their influence on the final result of the company. Therefore, initially set the performance criteria capable of realistically and accurately represent the relationship of the prestige of a post with the overall emergent effect of the organization. Often, such criteria are the degree of self-organization and self-control, responsibility, level of competence, boundaries of interference of an organizational decision, specificity of activity, impact on economic performance, etc. Thus, a hierarchical structure of interacting levels, functional responsibilities and rights is formed, which is based on monitoring the degree of mutual influence of the position and the synergistic process of the whole company.

Taking into account the strategic differences and the versatility of organizations and industries, the grading system can simultaneously coexist with other forms of staff motivation - a system of incentive payments, fringe benefits, medical care, social guarantees.

The procedure for introducing a grade system in organizations is as follows:

1) an analysis is performed to determine the organization's grade;

2) a category is established that includes the position;

3 ) set the grade position in the category system. The third procedure requires the highest level of competent assessment, since it determines the importance of the position for the strategic development of the organization.

The most relevant technologies of grading are the methods "Hey Trup" and "Watson Wyatt".

The method proposed by researcher Edward Haye is the most versatile. It is based on a system of developed tables, where the structure of interacting indicators of organization synergies is the decisive criterion for the emergence of a position. In this embodiment, the grade level is determined by evaluation tables, including several parameters representing the following components of performance monitoring: know how, problem solving; accountability.

The "Watson Wyatt" method is more focused on determining grades in the management structure, although it is adapted for monitoring both managerial and ordinary positions. The first stage of the technology consists of defining job categories; the second is the monitoring of these positions and the establishment of grades in the structure of the Grade Mar; the third is the formation of a unified stratification system of positions for various organizations and industries. Distribution by the levels of this system is carried out by monitoring all positions for the following functional factors of any company, regardless of the sphere of production or industry:

- functional knowledge;

- business expertise;

- leadership;

- problem solving;

- nature of impact;

- area of impact;

- interpersonal skills.

The technology of grading "Hay Troup" has established itself as the most universal and 
accessible for the analysis of any categories of workers. The disadvantages of this method include the complexity of the monitoring table system. The technology "Watson Wyatt", on the contrary, is focused on monitoring the management and administrative personnel of transport companies. However, when forming its own grading system, most of the recommendations of the Hay Troup technology were used. This applies, for example, to monitoring the correctness of a found profile: indicators of a general profile are converted to percentages (the aggregate of all factors is $100 \%$ ), then compared with tabular ones.

Thus, the main task of all grading methods is to solve the main problems of the management of organizations, in order to increase profits and competitiveness by the effective use of human resources. With the exception of some differences, grading is based on the general idea of determining the significance of a position for an organization.

\section{Results}

The use of monitoring the quality of human resource in the transport companies of the city of Tyumen - Evrobus 72, IntelInvest, ComfortAuto Tyumen, as well as the use of textual and graphical materials of reports allowed us to identify the following features.

The coefficient of consistency of personnel $(1,3122$ or $13.12 \%)$ of the transport companies indicated above was calculated (Table 1), which clearly shows the process of staff turnover

Table 1. The coefficient of consistency of personnel of the transport companies.

\begin{tabular}{|c|c|c|c|c|}
\hline \multirow{2}{*}{ Indicator } & \multirow{2}{*}{2017} & \multirow{2}{*}{2018} & \multicolumn{2}{|c|}{ Deviation } \\
\cline { 4 - 5 } & & 285 & -89 & Total \\
\hline Number of employees & 374 & $1 \%$ \\
\hline
\end{tabular}

According to traditional practice, this ratio should not exceed 1.0. The obtained value indicates that the personnel structure of the specified transport companies of the city of Tyumen is not sufficiently stable, although, in general, it is not critical for this sphere.

To improve the efficiency of the human resources management system of the transport companies of the city of Tyumen, a sociological survey was conducted based on a questionnaire of employees. The questionnaire "Study of the motivational component and the level of staff satisfaction" was used.

186 people took part in the survey, 82 of them were specialists from transport companies and 104 were drivers.

By analyzing the personal data, the following results of the assessment of the level of satisfaction of personnel with the human resources management policies of transport companies were obtained. So, employee satisfaction:

1) working conditions - the average level;

2) wages - average level;

3) motivation - the average level;

4) psychological climate in the team - a high level;

5) conditions for self-development and self-realization - low level;

6) non-material motivation - low level.

Thus, the overall satisfaction with human resource management in the assessments of the subordinates is at an average level.

An empirical study has revealed a number of problems related to the management of human resources of transport companies:

- financial and economic incentives are the main motivational factor for employees;

- More than half of employees claim that they lack motivation for work and moral encouragement; as a suggestion, employees offered to use the results of work as a model, letters, praise, they also appreciate the personal positive assessment of the manager. 
- $57.3 \%$ of respondents consider it necessary to improve the efficiency of human resource management in their companies;

- $34 \%$ of respondents believe that the current human resources management policy does not affect their work activities;

$-53 \%$ believe that management does not fully use their professional capabilities;

- $86 \%$ of employees have to work outside office hours and $68 \%$ are negative about this;

- the company's image and reputation is not a motivating factor of professional activity;

Also there was revealed the difference in answers between specialists and drivers to questions relating to the propensity for opportunistic behavior.

Question: In the absence of direct instructions from your manager during the shift, you will:

- experts answered: I go to my supervisor - 24\%; I find work myself - $76 \%$;

- drivers answered: I go to my supervisor - 78\%; I find work myself - $22 \%$.

Question: If you do not have control of the manager, then you:

- Experts answered: I also work with high quality - 28\%; I work with half the power $58 \%$, they will try not to work at all - $14 \%$;

- drivers answered: I also work qualitatively - 66\%; I work with half the power - $18 \%$; try not to work at all - $16 \%$.

These results indicate a tendency toward opportunism among the personnel of transport companies.

As a result of analyzing the information obtained by the method of individual interviews with employees of companies, the following problems were identified in the practice of human resource management:

- authoritarian management style, when the majority of decisions are made by the leader alone, without coordination, based on his personal experience and opinion;

- unified, fairly rigid organizational structure.

Among the factors that are most motivating and stimulating to perform work duties (the ability to manage large numbers of people, welfare growth, career growth, freedom of action, power and influence, security, a sense of confidence and stability, selfimprovement), employees identified a sense of confidence and stability, career growth (Fig.2).

Among the factors affecting the choice of work, employees mainly noted that their salary qualification was appropriate, as well as the availability of qualified medical care and social protection.

The main methods of human resource management of the transport companies Evrobus 72, IntelInvest, ComfortAuto Tyumen are administrative, financial and economic. Innovative methods based on the use of the idea of developing corporate culture and sociopsychological means of motivation are individual in nature and are more often used in private interactive communications between an employee and his immediate manager.

Thus, the results of the study are the empirical basis for the formation of a more effective policy of personnel management in the transport companies of the city of Tyumen.

\section{Discussion}

Development of an innovative system of motivation and incentives for employees of the transport sector.

The motivational factor (motif - from the French. Motive to action, motivating force) is the main resource for the effective management of human resources and encouraging employees to high-performance work. The professional motivation of a person consists of his personal orientation and psychological readiness for the qualitative performance of his 
duties and the exclusion of any opportunistic manifestations and simulation of activity. These social and ethical intentions are formed as a result of the systematic work of management structures for the implementation of the innovation policy of modern management. The use of stimulating resources, in turn, is an external, formal impact on personnel to ensure motivation. Such a distinction between motivational and stimulating factors is carried out only within the framework of a theoretical analysis; in practice, human resources management, they are used as interoperable management tools.

Most Russian transport companies still use inefficient, outdated management methods that are not only ineffective in motivating a modern employee, but also give rise to multiple manifestations of the anomic state of the entire socio-economic system. Therefore, it is necessary to implement the improvement of motivational and stimulating technologies correctly in a timely and phased manner [3-4].

1. The first stage begins with the identification of existing problems in the company and the definition of its strategic goals. Then, on the basis of the previous analysis, the goals of introducing innovative technology to stimulate staff are formulated. For example, an increase in financial and economic profit; ensuring timely and quality execution of orders; the retention of highly skilled and difficult replaceable workers; the introduction of a motivating remuneration system; creating conditions for independent influence on personal income level; the introduction of a mentoring program to increase the level of competence of young employees, etc.

2. The goal of the second stage is to investigate how effective is the personnel management system existing in the company. Most often, as a result of this monitoring, Russian companies come to the conclusion that the traditional management system is not efficient enough in the context of modern reality. Indeed, under the condition of a fixed salary, depending on the amount of working time, it is difficult to achieve from the employee a real increase in labor efficiency, and, consequently, the maximum level of profit that the owner of the transport company defines as the main goal.

3. The third stage is the identification of problems that impede the establishment of conformity between the interests of the employees and the employer. Most often disagreements exist in matters of wages. Taking into account the fact that narrow specialists of the transport sector are in demand and highly paid, the staff may demand a wage increase, while the employer also remains in the conditions of the economic crisis in the country and strives to minimize their costs.

Another problematic aspect in creating an effective human resource management system in the transport sector is its multi-level structure. If you can create a universal reward mechanism for ordinary drivers and low- and mid-level specialists, then highly qualified specialists need a special management system. In this regard, in some transport companies, Regulations are developed on the payment of remuneration and compensation to members of the company's board of directors. For example, this practice was introduced in JSC FGK. Another company, OJSC Independent Transport Company, the leader of the transport market in Russia and part of UCL Rail, a subholding, has introduced an innovative system of motivation and incentives for personnel. Its main features are: monitoring the effectiveness of the CEO's management directly depends on the amount of dividends paid to a shareholder; the use of market principles in evaluating the work of managers taking into account the value of the company's shares; a bonus program has been introduced that distributes all payouts through a system of coefficients that are determined individually for each manager [5-9].

Another example of the introduction of innovations into the incentive management system is the Management Company "Transportation Management Center", where the general director is a member of the board of directors. This gives him additional resources to influence the development of the company and participation in making strategic 
decisions. As a result, he owns shares in the company and the bonus program for the payment of annual dividends, their amount directly depends on its effective management, is applied to it, and it is the main factor of stimulation system.

The non-material form of incentives, defined as more complex in practical implementation, should be sufficiently flexible, taking into account age, gender identity, socio-psychological characteristics, individual needs and inclinations of individual employees. In this case, the development of a social package and additional social benefits and guarantees, social protection can be a motivating factor [10-13].

\section{Conclusion}

Ensuring the financial and economic sustainability, competitiveness and profitability of any company of the transport industry is impossible without an adequate strategy for managing human resources. The presented models and strategies of personnel management reflect the impact of the process of improving key indicators of the effectiveness of human resources on the sustainability of the transport sector. In addition, these models allow us to objectively evaluate all major aspects of a driver's work, to analyze the most effective factors affecting his professional competence level.

To increase labor productivity and reduce labor intensity, the following measures can be taken:

1. Improving the organization of the workflow for staff: recalculation of labor standards, the use of reserves to improve the comfort of the driver's workplace, etc.

2. Increasing technical capacities: replacing old equipment with more powerful and productive ones, using the inventions of scientific and technical progress to increase the technical capacities of equipment.

3. Reduction of non-productive costs: reduction of working time losses, preventive checks of equipment operation, which will prevent equipment breakdown.

4. Improving the skills of workers: employee training, seminars, training courses.

5. Optimization of production structure: optimization of the production process in accordance with modern methods and principles of organization.

The presented methodologies can be applicable not only for monitoring driver performance, but also for evaluating workers at any level of the transport sector, provided the model is adapted to the specifics of official duties.

In order to improve the performance of drivers, maintain their socio-psychological health, as well as the desire for continuous professional self-development, we recommend using the following types of incentives:

- traditional types of remuneration - official gratitude, flexible working hours; awards;

- Intensive - visual types of remuneration - a video, a publication about an employee and his professional successes, a sign with an engraving of the name of the employee, a priority when planning work shifts and rest time;

- non-standard types of rewards - the first priority when going on vacation, extra time to rest.

One of the main aspects of human resource management of transport companies is also the formation of an effective youth personnel policy. After all, young people are the basis of the human resource potential of the entire transport sector.

Thus, there is a need for an innovative system of human resources management in the transport sector. The solution of this task depends on the development of the field of management, which integral aspects are the development and implementation of a motivation system aimed at achieving strategic goals. When planning effective motivation in a transport enterprise, managers should pay attention to the mechanism for its implementation and monitoring of results. 


\section{References}

1. G.I. Baymambametova, K.E. Bukharova, Bulletin of the Kazakh Academy of Transport and Communications 1(68), 52-58 (2011)

2. A.V. Davydov, N.B. Popova, Scientific problems of transport in Siberia and the Far East 1, 55-60 (2012)

3. N. Zotkina, M. Gusarova, A. Kopytova, Advances in Intelligent Systems and Computing 692, 1204-1213 (2018) DOI: 10.1007/978-3-319-70987-1_129

4. D.T. Khvichiya, Car. Road. Infrastructure 3(17), 12-15 (2018)

5. A. Minnullina, MATEC Web of conference. International Science Conference SPbWOSCE-2016 "Smart City" 106, $08067 \quad$ (2017) doi: $10.1051 /$ matecconf $/ 201710608067$

6. A. Kopytova, MATEC Web of Conferences 106, 08056 (2017) DOI: $10.1051 /$ matecconf $/ 201710608056$

7. A. Minnullina, IOP Conference Series: Earth and Environmental Science 90, 012089 (2017) doi:10.1088/1755-1315/90/1/012089

8. N. Zotkina, A. Kopytova, M. Zenkina, O. Zhigunova, MATEC Web of Conferences 106, 08058 (2017) DOI: 10.1051/matecconf/201710608058

9. A. Minnullina, A. Mottaeva, IOP Conference Series: Earth and Environmental Science 90, 012123 (2017) doi:10.1088/1755-1315/90/1/012123

10. G.A. Langueva, E.A. Kotova, Transport. Economy. Social sphere (Actual problems and their solutions) Collection of articles of the International Scientific and Practical Conference 1, 81-84 (2018)

11. A.V. Kopytova, N.S. Zotkina, I.G. Reshetnikova, MATEC Web of Conferences 239, 04012 (2018) DOI: 10.1051/matecconf/201823904012

12. O. Frolova, A. Kopytova, E. Matys, MATEC Web of Conferences 170, 01064 (2018) DOI: $10.1051 / \mathrm{matecconf} / 201817001064$

13. M.L. Marinov, Transport of Russia: Problems and Prospects - 2016 materials of the International Scientific and Practical Conference 1, 185-193 (2016) 